\title{
METODOLOGIA DE PESQUISA DE BLOGS DE POLÍTICA \\ ANÁLISE DAS ELEIÇÕES PRESIDENCIAIS DE 2006 E DO MOVIMENTO "CANSEI"
}

\author{
Cláudio Luis de Camargo \\ Penteado
}

\author{
Marcelo Burgos \\ Pimentel dos Santos
}

\author{
Rafael de Paula Aguiar \\ Araújo
}

\begin{abstract}
RESUMO
No estudo das relações entre política e internet, os blogs podem ser compreendidos enquanto espaço de comunicação e ator político que trazem uma nova dinâmica para as relações sociais. O presente estudo discute o uso dessa nova ferramenta e suas implicações para a compreensão do jogo político na contemporaneidade. Entendendo a necessidade de pesquisar o fenômeno dos blogs de política, apresentamos uma nova proposta metodológica capaz de auxiliar a análise da estrutura do blog, suas mensagens (mensagens) e a sua interatividade. A fim de testar os instrumentos de análise, acompanhamos alguns dos principais blogs durante as eleições presidenciais de 2006 e o debate do movimento "Cansei". Foram verificadas, além do debate político na blogosfera, as diferenças de abordagem de acordo com o perfil do 'blogueiro', avaliando os estilos, as perspectivas e os formatos dos blogs, cujos autores possuem históricos diferenciados. Também foram analisados os temas e os enquadramentos das mensagens (mensagens) e comentários. A análise, em geral, gira em torno do posicionamento político dos participantes, muitas vezes deixando de lado o tema central proposto pelo 'blogueiro'. Foi comprovada a hipótese de que os blogs são importantes ferramentas capazes de ampliar a participação política, mas que, efetivamente, os debates estabelecidos nos fóruns de discussão são superficiais, caracterizados pela falta de qualidade dos argumentos, presença de avaliações morais, ausência de propostas e análises críticas. O artigo apresenta os principais resultados da análise, discutindo o papel dos blogs de política para o desenvolvimento da democracia, e comprova a eficácia do método desenvolvido.
\end{abstract}

PALAVRAS-CHAVE: blogs; blogosfera; democracia; política; metodologia de análise.

\section{INTRODUÇ̃̃O}

Este artigo nasce da necessidade de desenvolver ferramentas (assim como suas aplicações) para o estudo das Novas Tecnologias de Informação e Comunicação (NTICs), em especial, os weblogs; um fenômeno relativamente recente de comunicação que vem conquistando novos adeptos dentro da rede mundial de computadores, a internet. Hoje, os blogs exercem significativa importância dentro do universo social, extrapolando o espaço virtual da internet para o cotidiano. A diversidade de usos dos blogs possibilitou que esses dispositivos ampliassem sua relevância social, deixando de ser apenas diários on-line de adolescentes e espaço de mídia alternativa para consolidarem-se como um novo espaço comunicativo e um novo meio de ação social que a cada dia conquista um número maior de leitores e cria um pú- blico cativo para a discussão de seus conteúdos.

Segundo o relatório State of Blogosphere 2008, do sítio Technorati (2008), responsável por monitorar os blogs na internet, a blogosfera registrou em 2008 o número recorde de 133 milhões de blogs indexados pelo sítio desde 2002. O relatório ainda indica que em média são publicados 900000 mensagens por dia. Esses dados indicam que os blogs já fazem parte do dia-a-dia da comunicação na internet, tornando-se um grande fenômeno comunicativo.

Nascidos na forma de diários on-line, os blogs atualmente constituem uma rede de produção, circulação, transmissão e debate de informações, formando comunidades de 'blogueiros' e alimentando um novo público que busca fontes alternativas de informação que complementem as tradi- 
cionais, bem como promovendo o debate entre os 'blogueiros' e os leitores por meio dos fóruns de comentários. Os blogs oferecem aos visitantes olhares distintos para os acontecimentos, novas interpretações e novas informações, muitas vezes publicadas no calor dos fatos, e permitem que os usuários emitam comentários sobre os temas abordados.

Verifica-se, portanto, duas importantes características da internet: a possibilidade da interatividade entre o emissor das mensagens e os receptores e a capacidade dos usuários da rede produzirem conteúdos. Isso permite que pessoas comuns possam comentar as notícias publicadas, promovendo o debate por meio das infovias da comunicação, além de possibilitar que cada um, com um mínimo de conhecimento sobre a internet $^{1}$, possa criar seus próprios blogs para divulgar suas idéias e pontos de vista.

Alguns blogs constituem-se em um novo modelo de jornalismo, mais ágil e pessoal, mais especializado e interativo, configurando-se como um novo formato de atuação jornalística (ALDÉ \& CHAGAS, 2005) e como um novo ator político dentro das relações sociais, ao produzir e comentar informações e promover o debate em torno das mesmas (PENTEADO, SANTOS \& ARAUJO, 2008). O formato do blog pode também funcionar acolhendo (por meio de compilação e comentários) as informações e notícias da atualidade, caso em que o 'blogueiro' funciona como um mediador, selecionando e filtrando o grande número de informações que circulam na rede. Nessa modalidade, os blogs agregam detalhes e considerações que proporcionam outro valor à informação original, amplificando seu significado e sua repercussão.

Uma característica importante dos blogs é sua capacidade de alimentar rapidamente seus usuários com notícias e análises de fatos, causando a impressão de instantaneidade. A capacidade de explorar a velocidade de publicação da internet,

\footnotetext{
1 Atualmente, na internet, existem diversos sítios que oferecem aos seus usuários uma plataforma para que cada um crie um blog pessoal gratuitamente. Como exemplo podemos citar o Bloguer (disponível em https:// www.blogger.com/start, acesso em 16.jul.2009). Os formatos disponíveis são fáceis de serem operados, o que possibilita a entrada diária de novos 'blogueiros' na Web.
}

possibilitando aos usuários dos blogs estarem a par das últimas notícias é um de seus maiores atrativos. Pode-se afirmar então que os motores do blog são: seu conteúdo, a atualização de suas informações e a sua credibilidade (tanto da notícia como do 'blogueiro').

Outro atrativo do blog está relacionado ao fenômeno de fragmentação da mídia, por meio do qual as pessoas buscam as fontes de informação com as quais mais se identificam. Os blogs passam a ser espaços de comunicação especializados em determinados assuntos, geralmente relacionados ao perfil do 'blogueiro'. Nesse sentido, podemos afirmar que os blogs situam-se em uma nova configuração, caracterizada pelos fluxos das informações, que cria novas possibilidades de interação social.

Os blogs criaram uma rede de informações e comunicação alternativa às mídias tradicionais. É o que se percebe com as diversas comunidades de blogs que têm formado-se nos últimos anos, que compõem o que se convencionou chamar por blogosfera. De forma geral, a blogosfera é composta por 'blogueiros' independentes que criam suas redes e promovem debates, discussões e ações à margem da mídia tradicional e dos grandes portais da internet.

As notícias dos principais blogs já foram incorporadas pelo jornalismo on-line. Elas estão presentes nas chamadas dos grandes portais de notícias, com hiperlinks de direcionamento para os blogs. Há um destaque dos blogs em relação ao jornalismo on-line pela pessoalidade das opiniões e pela "independência" do 'blogueiro'. O posicionamento pessoal do autor muitas vezes atrai os visitantes interessados em saber uma opinião fora das linhas tradicionais dos editoriais coorporativos, ou então serve como referência intelectual para os usuários fazerem a leitura dos acontecimentos. Dessa forma, os blogs que fazem apenas uma simples compilação de notícias em geral não atraem muitos acessos, pois não apresentam um ponto de vista consolidado. Isso não ocorre necessariamente com os blogs de jornalistas tradicionais que, por sua experiência anterior, possuem um capital simbólico que lhes garante maior número de acessos.

Observa-se, nos últimos anos, uma grande migração de jornalistas consolidados na imprensa tradicional que adotaram os blogs como um novo 
meio de comunicação. No Brasil, podemos citar como exemplo nomes como o de Ricardo Noblat, Josias de Souza, Luiz Nassif, Reinaldo Azevedo, entre outros. Esses ‘blogueiros', diferentemente do que ocorre com os chamados independentes, acabam, por vezes, constituindo uma equipe que os ajuda na divulgação e apuração de notícias. Alguns fazem parte dos principais grupos de mídia tradicional e/ou dos portais de internet, o que de certa forma rompe com o ideal de independência do autor e da construção de uma rede alternativa de informações à corrente hegemônica da mídia.

\section{REDES SOCIAIS, CIBERATIVISMO EAÇÃO POLÍTICA NA BLOGOSFERA}

A mídia tradicional é uma fonte de informação vertical, ou seja, dos emissores para os receptores. As NTICs, por sua vez, possibilitam aos receptores serem também produtores de informações. Com isso é possível ponderar uma nova relação de forças que pode ser considerada mais horizontalizada, se comparada com a dinâmica propiciada pela mídia tradicional. No Brasil há coletivos em que diversos 'blogueiros' reúnemse para formalizar uma rede de troca de informações e notícias independentes dos grandes veículos de comunicação ${ }^{2}$.

Na mídia tradicional, a informação, até ser veiculada, passa por diversos filtros hierárquicos de edição (gatekeepers) podendo assumir, inclusive, uma edição final diferente daquela que foi imaginada por seu autor. Com as NTICs, em especial os blogs, isso dificilmente acontece. Os indivíduos têm maior liberdade para publicar o material que desejam sem precisar passar por um editor.

A maior liberdade de produção de informação pode levar a uma maior participação política via internet. Um exemplo seria o fenômeno conhecido como netroots, ativismo político de "raiz", que é organizado com as NTICs, constituindo-se enquanto modelo de incorporação dos usos dessas novas tecnologias pela democracia representativa. Ou seja, diferente do que ocorria no século anterior, o ativismo político hoje realiza-se $n a$ e pela mídia, na ágora virtual, em vez da ágora concreta das cidades, transformando os mecanismos da ação política.

2 Exemplos dessas comunidades são: www.wordpress. com, www.sivuca.com e www.blogger.com; acesso em 16.jul.2009.
Cabe lembrar que desde fins do século XX a internet tem sido responsável por organizar manifestações políticas pelo mundo. Foram os sítios de mídia independente com o apoio de ONGs que organizaram as manifestações em Seattle e Gênova. Foi por meio do uso de celulares e envio de mensagens SMS que foram desmentidas as primeiras informações oficiais sobre o atentado à estação Atocha em Madri em março de 2004, véspera de eleições na Espanha ${ }^{3}$. Também foi por meio do uso de celulares e de blogs coletivos que os franceses organizaram os protestos que movimentaram o país, em fins de 2005. Os exemplos acima citados são a demonstração do novo ativismo político (netroots) que tem se realizado via internet.

Em uma sociedade em que a informação passou a ser matéria-prima para a política (CASTELLS, 1999a), os blogs constituem-se em um novo espaço de ação, fora das instituições sociais estabelecidas, independentes dos meios de comunicação tradicionais ${ }^{4}$. Essa arena virtual cria novas possibilidades de interações e comunicação, como a formação de fóruns virtuais para debates entre seus usuários e novos mecanismos para a ação política. Contudo, é importante destacar que muitas vezes as discussões nos fóruns de comentários de mensagens são realizadas com base em ataques pessoais, demonstração de preconceitos e uso de humor grosseiro, algumas vezes, inclusive, desviando o foco do debate e mudando o assunto, o que contribui para problematizar o ideal dos "ciberotimistas" de que os blogs são espaços que desenvolvem a democracia.

Os dados e opiniões publicados nos blogs assumem o papel de referências informacionais e podem exercer influência sobre a opinião pública. Segundo Castells (1999b), os temas políticos não exercem grande atração dentro da agenda social. A grande maioria da população tem pouco interesse e pouco conhecimento sobre a temática.

\footnotetext{
3 Segundo Sampedro (2005), o uso das NTICs foi decisivo para dar a vitória ao candidato da oposição, Zapatero.

4 Existe uma discussão a respeito da independência dos blogs hospedados em grandes portais e sítios de grandes grupos de mídia. Haveria, nesse caso, a possibilidade de interferência, ainda que menor, no conteúdo e teor das informações publicadas.
} 
Dessa forma, as análises realizadas pelos 'blogueiros' funcionam como referências pelas quais os usuários compreendem o universo da política e entram em contato com seus temas e discussões.

O aumento da ação política pelos blogs está associado ao desenvolvimento tecnológico. No Brasil, calcula-se que o número de internautas acima dos 16 anos de idade já chegou a 39 milhões; número que aumenta a cada ano devido às mais diversas iniciativas que vão desde a instalação de acesso à internet em escolas públicas, ao crescimento de lan houses e à aquisição de novos computadores (tanto computadores de mesa como notebooks) (Em um ano, número de internautas residenciais cresce $50 \%$ no Brasil, 2008). Além disso, diversas esferas de governos possibilitam acessos por meio de programas como Tele Centros e Acessa SP.

Tudo isso faz que as pessoas passem cada vez mais tempo navegando pela internet. Atualmente o brasileiro navega, em média, quase 24 horas por mês, ficando a frente de países como França, Estados Unidos e Austrália (idem).

Pesquisa do IBOPE-NetRatings afirma que o número de internautas que acessam a internet em sua própria residência aumentou $14,5 \%$ de dezembro de 2007 para dezembro de 2008, atingido a marca de 24,5 milhões de brasileiros. A mesma pesquisa indica que o número de leitores de $b \operatorname{logs}$ teve um aumento relativo ainda maior, atingido 11,6 milhões de pessoas em dezembro de 2008, um aumento de $22,1 \%$ em relação ao ano de 20075 .

$\mathrm{Na}$ esfera política podemos identificar ainda outros usos da blogosfera. Os blogs podem funcionar como espaço de divulgação de informações de "bastidores", quando jornalistas e 'blogueiros' independentes utilizam suas fontes para transmitir notícias internas do universo da política. Os blogs de política no Brasil ganharam popularidade com a cobertura dos escândalos do primeiro governo Lula, em especial a cobertura do escândalo do "mensalão". Segundo os sítios que medem os acessos dos usuários, esse período registrou um aumento significativo no número

5 Para mais informações, cf. NÚMERO DE BRASILEIROS QUE LÊEM BLOGS CRESCE EM 2008, 2009. de visitas aos $b \log s^{6}$, o que Aldé, Escobar e Chagas (2006) chamaram de "febre dos blogs de política".

Um exemplo da importância dos blogs, como espaço de comunicação e como ator político, pôde ser verificado nas eleições de $2006^{7}$ no Brasil. Os principais $b \log s$ de política participaram ativamente da cobertura, por meio de análises das campanhas e divulgação das notícias políticas, disponibilizando em seus canais comentários e informações para abastecer um público ansioso por informações. Algumas das notícias do período foram divulgadas primeiramente pelos blogs para somente depois repercutirem na mídia tradicional. Como o caso em que o jornalista Paulo Henrique Amorim ${ }^{8}$ revelou em seu sítio um áudio sobre o vazamento das fotos da Polícia Federal com o dinheiro da suposta compra de dossiê contra o candidato José Serra, divulgadas pela mídia tradicional. Também podemos citar o exemplo do humorista italiano Beppe Grillo que conseguiu mobilizar, por meio de seu blog, 50 mil pessoas em um movimento contra os privilégios dos mandatários em seu país 9 .

Os blogs podem também pautar a agenda dos políticos. Um exemplo foi quando o jornalista Ricardo Noblat publicou uma cobrança de posicionamento do Senador Pedro Simon sobre o suposto dossiê dos gastos com cartão corporativo, por parte da ex-primeira-dama, Ruth Cardoso. O Senador, mais tarde, retornou à tribuna do Senado Federal e teceu seus comentários sobre o caso. Mais recentemente, o ‘blogueiro' e jornalista Marcelo Leite publicou em seu blog uma crítica aos dados de educação apresentados pelo Presidente Lula em discurso. $O$ fato gerou uma calorosa discussão entre o 'blogueiro' e o Secretário de Imprensa da Presidência da República, Nelson Breve (cf. ANALFABETOS EM NÚMEROS, 2009).

6 Os principais sítios que verificam o número de acessos de blogs são: www.technorati.com, www.alexa.com, www.blogpulse.com e www.blogblogs.com.br. Acesso em 17.jul.2009.

7 Conforme analisado por Penteado, Santos e Araújo (2007a e 2007b).

8 Atualmente disponível em: www.paulohenriqueamorim. com.br; acesso em 17.jul.2009.

9 O blog do Beppe Grillo está disponível em www.beppegrillo.it; acesso em 6.ago.2009. 
Essa intervenção dos blogs na agenda de políticos expressa um importante poder de atuação na esfera política contemporânea, pois mesmo ainda tendo um número limitado de leitores, eles possuem uma audiência qualificada, o que amplifica sua repercussão para outras pessoas ${ }^{10}$.

Na última campanha presidencial norte-americana, em 2008, os blogs, além de fonte de informações privilegiada, constituíram-se em um elemento chave da estratégia de campanha; na divulgação de mensagens, na interação com o eleitorado e nos ataques aos opositores. O uso dos blogs nas campanhas estadunidenses teve início com o pioneirismo do pré-candidato democrata, Howard Dean, que soube utilizar a internet para dinamizar sua campanha, sendo inclusive o primeiro candidato a criar o seu próprio blog (Blog for America), na campanha de 2003. O blog do candidato chegou a atingir a marca de 30000 visitas por dia em setembro de 2003 (GILL, 2004).

No Brasil, os blogs também são utilizados por candidatos e políticos como uma nova forma de divulgação de idéias. Como exemplo, podemos citar os blogs de César Maia ${ }^{11}$, José Dirceu e Soninha Francine. Os blogs também são utilizados como ferramenta de campanha, conforme pôde ser observado nas últimas eleições, quando os principais candidatos a prefeito de São Paulo, por exemplo, tinham um blog em seu sítio oficial. Contudo, os blogs de políticos e candidatos brasileiros ainda não têm a mesma repercussão que têm nos EUA.

Outro uso de blogs como ferramentas políticas são os warblogs. Durante a invasão do Iraque em 2003 pelas tropas americanas e inglesas, jornalistas, soldados e a população local relatavam suas experiências em seus blogs pessoais, os chamados warblogs (KAHN \& KELLNER, 2004). Um exemplo importante desse tipo de 'blogueiro' foi $o$ arquiteto iraquiano que, sob o pseudônimo de

10 Em conversa recente na Campus Party de 2009, a pesquisadora e professora Sandra Montardo, uma das organizadoras do livro Blogs.com, expôs suas idéias em conversa com os autores.

11 César Maia, ex-prefeito do Rio de Janeiro teve um polêmico blog no qual fazia comentários sobre a vida política do país. Agora mantém o que ele chama de ex-blog, fornecendo seus comentários para as pessoas cadastradas, em forma de newsletter.
Salam Pax, informava direto de Bagdá os acontecimentos da Guerra do Iraque ${ }^{12}$. Podemos citar também o caso do 'blogueiro' palestino, Sahme Habeeb, que cobriu a invasão israelense na faixa de Gaza.

No entanto, como qualquer ferramenta, os blogs dependem do uso que as pessoas fazem deles. Assim, seu potencial político e informacional fica limitado ao processo de apropriação social dos autores e dos leitores. Nesse sentido, entendemos a necessidade de desenvolver pesquisas para avaliar os impactos dos blogs no universo político contemporâneo.

Dentro deste universo, que compreende o blog enquanto espaço informacional e mecanismo de ação política, as pesquisas sobre comunicação assumem diversas possibilidades para as Ciências Sociais, dentre as quais se destacam: (1) avaliar as transformações introduzidas por essa nova tecnologia de comunicação; (2) verificar seu potencial de influência política; (3) examinar os fóruns de debates como uma forma de construção ou reconstrução da esfera pública; (4) investigar se os blogs podem ser considerados uma mídia alternativa; (5) apurar se as informações publicadas nos blogs podem ser consideradas como uma forma de expressão da opinião pública; (6) estudar suas possibilidades de promoção da democracia e (7) analisar a configuração de uma nova cidadania (cidadania virtual).

\section{CAMINHOS PARA A PESQUISA SOBRE BLOGS DE POLÍTICA}

Para o desenvolvimento de pesquisas sobre esse novo objeto foi necessário construir um método que fosse capaz de dar conta da complexidade do universo dos blogs. Sua criação surgiu de uma necessidade prática. Durante o desenvolvimento de uma pesquisa sobre a cobertura dos blogs no processo eleitoral de 2006, percebemos que não havia uma metodologia específica para $o$ estudo de blogs de política. As metodologias encontradas na ocasião eram de avaliação e estudo de sítios de política ou estudos analíticos sobre blogs (LANDTSHEER \& NEUNER, 2000; RECUERO, 2003; LEMOS et alii, 2004;

12 Essa informação foi-nos passada pelo Prof. José Luis Dader da Universidad Complutense de Madrid. A metodologia proposta neste artigo foi amplamente discutida com o Professor Dader, a quem agradecemos. 
NICOLÁS, MADRIAGA\& TUCHO, 2004; ALDÉ \& CHAGAS, 2005; ALDÉ, ESCOBAR \& CHAGAS, 2006; BRAGA, 2006; NICOLÁS, MADRIAGA \& TUCHO, 2006), mas que não se adequavam à análise desses blogs específicos ${ }^{13}$.

Entendemos por blogs de política aqueles que disponibilizam em suas páginas eletrônicas mensagens sobre assuntos políticos, podendo ser informações, debates, comunicações ou formas de ativismo. Assim, os blogs de política compreendem boa parte da blogosfera, que envolve jornalistas políticos, ativistas, acadêmicos, candidatos a cargos públicos e pessoas de forma geral com interesse em política.

Para atender às diversas possibilidades de pesquisas sobre o objeto, foi necessário construir algumas ferramentas analíticas que fossem capazes de articular as hipóteses de pesquisa com a coleta de dados para o estudo científico. O método proposto consiste em cinco etapas, que apresentamos a seguir: (1) histórico e descrição do blog; (2) classificação dos blogs; (3) análise da estrutura do blog; (4) análise do conteúdo das mensagens e (5) análise da interatividade ${ }^{14}$.

\section{III.1. Histórico e descrição dos blogs}

A primeira etapa do método proposto implica na contextualização do $b l o g$. Consultamos os seus arquivos e estudamos o perfil de seu autor tendo em vista as características que acabam por influenciar diretamente o seu funcionamento. Essa etapa é fundamental para compreender o funciona-

13 Outra dificuldade encontrada foi a falta de consenso sobre uma definição de blog. A inexistência de uma definição comum faz que exista muita controvérsia a respeito dos blogs. Assim, optamos por assumir um conceito mais prático e disseminado na internet, adotando o mesmo conceito utilizado pelo sítio de monitoramento de blogs Technorati: um blog é um sítio de internet, geralmente mantido por uma única pessoa, mas podendo ter vários responsáveis, com atualizações regulares de comentários, descrições de eventos ou outros materiais (gráficos, vídeos, sons etc). As atualizações são publicadas em ordem nãocronológica.

14 A articulação das cinco etapas de pesquisa compõe o método de investigação dos blogs de política, podendo ser adaptada às necessidades do pesquisador. Para mais detalhes, cf. Penteado, Santos e Araújo (2006). A classificação, a análise da estrutura, do conteúdo das mensagens e da interatividade é realizada com o auxílio de quatro planilhas, apresentadas em anexo. mento do blog, identificar seus objetivos e as características pessoais de seu autor. Nesse momento também é feita uma descrição dos elementos estéticos, dos serviços e dos links existentes no blog.

\section{III.2. Classificação dos blogs}

A classificação proposta divide-se em duas partes: quanto à localização do blog e quanto ao perfil do 'blogueiro'. A criação de uma tipologia ou classificação dos blogs de política permite que o pesquisador diferencie a atuação dos diferentes blogs que atuam dentro da blogosfera. Cada blog de política possui uma especificidade que depende de sua constituição. Um blog dentro de um portal de informação da internet, por exemplo, tem uma identidade que está atrelada, mesmo que indiretamente, à política editorial do portal, atuando de forma menos independente. Por outro lado, um blog pessoal de um desconhecido tem maior liberdade de expressão e atuação ao preço de menor credibilidade. O perfil do 'blogueiro' também é uma importante característica. Uma vez que o blog nasce dentro do formato de diário on-line, a pessoa responsável por administrar o espaço é quem dá identidade ao blog; suas características pessoais é que vão formatar a atuação do $b \log$.

Quanto à localização do blog, podem ser classificados como institucionais, independentes e blogs de entidades da sociedade civil.

\section{III.2.1. Blogs institucionais}

a) Blog localizado em portais de internet ${ }^{15}$. Seguem, em sua maioria, um formato próximo ao jornalismo, valorizando a exposição de notícias e informações a partir de princípios de audiência. Os 'blogueiros' são, na maioria das vezes, jornalistas com uma trajetória profissional na mídia tradicional, possuem muito capital simbólico e seu reconhecimento foi construído fora da internet. A hospedagem do blog em um grande portal da internet aumenta a sua credibilidade; o internauta confere-lhe um status maior. A presença nos portais também amplia a visibilidade do blog, tornando-o mais conhecido e, conseqüentemente, aumentando seu número de acessos.

b) Blog localizado em sítio de mídia tradicional. Aqui se incluem os blogs relacionados às gran-

15 Os principais portais de internet no Brasil são: UOL, Terra, Globo, IG e Yahoo. 
des corporações da mídia tradicional que circulam por meio impresso (jornais e revistas) e digital (programas de televisão). As características desses blogs são semelhantes aos blogs de portais. Os sítios das empresas de mídia oferecem aos seus visitantes links para os blogs, seguindo o formato jornalístico. No entanto, a influência da linha editorial da empresa de mídia, nesse caso, é mais clara, assim como o apelo jornalístico do próprio blog em sua dinâmica de funcionamento. Os 'blogueiros' responsáveis pelos sítios são, em sua maioria, jornalistas da própria redação da empresa com maior destaque dentro do cenário midiático. Sua localização confere-lhe credibilidade, uma vez que o blog é associado à imagem da empresa e do próprio jornalista. Têm também maior visibilidade, pois estão expostos em sítios de grande visitação, o que lhes propicia um maior número de acessos.

c) Blog localizado em sitio de partido. São relacionados a partidos políticos e caracterizamse por serem espaços de exposição política e fóruns de debate. Eles servem para os partidos divulgarem suas idéias, defenderem seus interesses e entrarem em contato com a militância e com simpatizantes. Os textos e comentários são parciais e voltados para a defesa das bandeiras políticas do partido, procurando atrair novos militantes e divulgar suas propostas. A credibilidade dos blogs localizados em sítios de partidos é praticamente restrita aos seus simpatizantes e filiados.

\section{III.2.2. Blogs independentes}

São criados e gerenciados por pessoas desconhecidas do grande público e assumem o formato de diários on-line, em que os aspectos informais são valorizados. Seus autores têm maior liberdade para expressar suas opiniões e definir os assuntos a serem abordados. Os conteúdos exibidos não possuem uma padronização, mas percebe-se uma tendência de valorização da crítica à política e aos políticos, o uso do humor e da ironia. Por outro lado, a autonomia de criação confere a esses espaços pouca credibilidade, baixa visibilidade e seus acessos são mais restritos. Os acessos aos blogs independentes ocorrem a partir de uma rede de auto-referência criada entre os próprios 'blogueiros' e seus conhecidos, a chamada blogosfera. Dependendo do tipo de análise que se pretende realizar; cabe incluir uma subdivisão sobre a presença ou não de conteúdo ideológico.

\section{III.2.3. Blogs de entidades da sociedade civil}

Aqui se incluem os blogs criados e mantidos por organizações ou entidades da sociedade civil. Esses blogs assumem o formato de fórum de debates em torno de temas específicos, como meioambiente, combate à fome etc. Trata-se de um espaço de mobilização virtual que reúne pessoas interessadas na defesa de interesses sociais variados. Os conteúdos dos textos são voltados a uma temática, possuem caráter crítico, informativo e, muitas vezes, panfletário. Os comentários expostos são, geralmente, parciais, fragmentários e específicos. A credibilidade e visibilidade desse tipo de blog estão relacionadas à própria imagem da entidade e do responsável pelo blog. Em geral, seus acessos são mais restritos e atingem um público mais segmentado.

Os blogs também podem ser classificados de acordo com o perfil e a formação profissional do 'blogueiro'. É possível verificar o estilo e o formato do blog também a partir das classificações a seguir.

\section{III.2.4. Blogs escritos por jornalistas}

Dentre os jornalistas é possível identificar três categorias: (a) profissionais, que também trabalham para alguma empresa midiática; (b) freelancers, que trabalham com técnicas de recompilação e verificações profissionais e (c) independentes. Esses tipos de blogs seguem, em sua maioria, o formato do jornalismo tradicional, trazendo informações, comentários e opiniões sobre os temas políticos.

\section{III.2.5. Blogs escritos por políticos}

A característica central desse tipo de blog é a expressão da opinião individual do 'blogueiro' e seu posicionamento político. $\mathrm{O}$ formato pode ser o de blog jornalístico, ao comentar as informações da política, ou de diário on-line, ao relatar experiências e idéias particulares. Esses blogs, em geral, são um meio de interface entre o político e a população, funcionando como um novo espaço de comunicação.

\section{III.2.6. Blogs escritos por acadêmicos (professo- res, pesquisadores, escritores etc.)}

Esses blogs possuem um formato híbrido: informativo e analítico. Os temas e os conteúdos são selecionados pela área de atuação e interesse do acadêmico. Em geral, as análises são pontuais, feitas no calor dos acontecimentos, e não possu- 
em caráter científico. O estilo é pautado por um vocabulário sofisticado e pelo uso de referências e citações acadêmicas para justificar opiniões. Esses blogs possuem grande credibilidade junto aos internautas, que é construída pela formação acadêmica e percurso biográfico do autor. No entanto, possuem menos visibilidade.

\section{III.2.7. Blogs escritos por pessoas desconhecidas ou independentes}

Na maioria dos casos esses blogs seguem o formato de diário on-line. Por serem escritos por pessoas das mais variadas, eles não possuem um estilo único. Os 'blogueiros' desconhecidos têm total liberdade para expressar-se, podendo, inclusive, utilizar comentários preconceituosos, avaliações personalistas e parciais. $\mathrm{O}$ estilo da escrita desses autores é a inconstância de estilo, que valoriza a crítica direta e o humor. Blogs com pouca credibilidade e visibilidade, ficam restritos a um universo particular de conhecidos ou a redes criadas a partir da própria internet e que influenciam o número de acessos.

\section{III.3. Análise da estrutura dos blogs}

A análise da estrutura do blog permite examinar os serviços oferecidos e suas possibilidades enquanto instrumentos da prática política contemporânea. Os blogs, em sua maioria, estão estruturados em uma página principal, na qual são postadas as informações e análises do 'blogueiro'; mas também disponibilizam outros serviços para as pessoas que navegam no sítio: enquetes de opinião, imagens, banco de dados, charges etc.

Para a melhor aplicação do método proposto, foram elaboradas quatro planilhas a serem utilizadas nos estudos dos blogs. A planilha de análise ou codificação deve ser aplicada à página principal e às páginas internas, conforme a intenção do pesquisador. Segue abaixo a explicação dos conteúdos a serem observados pela planilha.

\section{III.3.1. Verificação das mensagens}

$\mathrm{Na}$ página principal concentram-se as principais características do blog. Ali são disponibilizadas as mensagens que guardam o conteúdo mais significativo do blog e constituem-se em informações que abrem espaços para a interatividade. Quanto às mensagens, é importante notar: (a) a periodicidade de suas publicações e atualizações; (b) se estabelecem links de hipertexto, dentro da mensagem ou não; (c) se há espaços para postagens externas (abertura para que outros utilizem o espaço do blog para escrever suas mensagens) e (d) a presença ou não de outros serviços.

\section{III.3.2. Interatividade}

Uma das características mais significativas dos blogs é a interação entre leitores e autores. Nessa interação deve ser observada: (a) a forma de interatividade (leitura, e-mail, fórum ou outra) e (b) se existem regras para a participação. Embora nem sempre essas regras sejam cumpridas, elas têm o intuito de normatizar o conteúdo das mensagens.

\section{III.3.3. Biografia}

Outro fator importante na primeira página é a biografia ou perfil do 'blogueiro'. Nesse espaço é possível encontrar uma breve descrição com a trajetória ou o curriculum vitae de seu autor. Em alguns casos existem detalhes mais pessoais sobre o autor, enquanto outros limitam-se a fornecer informações profissionais. É comum encontrar na página principal uma foto do 'blogueiro', mas nem sempre o autor ou os autores são identificáveis, sobretudo nos blogs independentes.

\section{III.3.4. Links}

Outro fator significativo é o número de links presentes. Os links podem direcionar o usuário para: (a) outros espaços virtuais dentro do próprio blog (em seu espaço interno) ou (b) espaços externos ao blog (outros blogs e sítios).

\section{III.3.5. Outros serviços}

Também é importante observar se existem espaços destinados a outros serviços, tais como: entrevistas, artigos, enquetes, imagens, arquivos para consulta ou download, informações úteis e outros. Os dois primeiros diferenciam-se das mensagens uma vez que tendem a ser mais elaborados e mais extensos. As enquetes são realizadas conforme o interesse e o perfil do 'blogueiro', não possuindo valor científico e podendo ser dirigidas para alcançar o resultado desejado ${ }^{16}$. As imagens podem ser charges, animações ou links

16 Alguns dos blogs controlam o endereço IP (Internet Protocol) do computador que participou da enquete e não aceitam que mais de um voto seja registrado pelo mesmo computador. Outros não têm esse controle e, portanto, 
para arquivos de áudio e vídeo, dentro das próprias mensagens ou fora delas. Os arquivos podem ser documentos escritos, fotos, áudios e vídeos disponibilizados para consulta ou para serem salvos pelos visitantes. Os blogs podem disponibilizar para seus usuários informações úteis como locais de votação, dados de pesquisas de intenção de voto, legislação eleitoral etc. Na categoria "outros" são inseridos os demais serviços encontrados dentro do blog.

\section{III.3.4. Análise do conteúdo das postagens}

Também é importante no estudo dos blogs de política a análise dos conteúdos expressos nas mensagens. O exame dos conteúdos possibilita verificar o posicionamento do 'blogueiro' diante de determinados assuntos, permitindo avaliar a forma de atuação dos diferentes blogs existentes. Para a análise do conteúdo é importante criar categorias para classificar o formato, tornando possível um agrupamento dos dados e a indicação de tendências. As categorias de análise criadas são apresentadas a seguir.

\section{III.3.4.1. Análise do conteúdo dos mensagens}

Uma mensagem poderá ser classificada quanto ao seu conteúdo. Poderá ser informativa direta, informativa indireta, opinativa, irônica, propositiva, conter uma avaliação moral, uma avaliação crítica e um posicionamento político ${ }^{17}$. Uma mesma mensagem poderá acumular mais de uma categoria possibilitando ao pesquisador reunir um número maior de dimensões da informação. Essas categorias de análise do conteúdo da mensagem poderão servir de guia para o olhar, orientando a atenção do pesquisador para aspectos importantes da informação, que podem revelar a intenção do 'blogueiro' e as possibilidades políticas de sua ação comunicativa.

mais de um voto pode ser registrado pelo mesmo computador; o que permite que uma mesma pessoa insista na opinião que mais lhe agrada, manipulando o resultado da enquete.

17 As categorias criadas aqui tiveram como base as obras de Mauro Porto (1999; 2002) e a análise e desenvolvimento feita pelos pesquisadores do Neamp (Núcleo de Estudos em Arte, Mídia, Política, PUC-SP) durante o Projeto Temático: Mídia, Campanha Eleitoral e Comportamento Político em São Paulo, financiado pela Fundação de Amparo à Pesquisa do Estado de São Paulo (Fapesp) e coordenado pela Prof ${ }^{\mathrm{a}}$. Dra ${ }^{\mathrm{a}}$. Vera Chaia. Para mais informações, cf. Neamp (2009) e Revista Aurora (2009). a) Informativa (direto e indireto). Trata-se de mensagens cuja intenção está restrita à informação de um fato, sem a emissão de juízos ou reflexões, podendo ser informativa direta, quando o próprio autor traz a informação, ou informativa indireta, quando o autor da mensagem traz uma informação cuja responsabilidade é de um terceiro. Uma mensagem informativa indireta traz consigo uma isenção do autor sobre a informação passada e, dependendo da autoria, garante uma maior credibilidade. Em geral, uma informação indireta funciona como argumentação de autoridade e traz dados novos à discussão. A informação indireta poderá ser, portanto, impulsionadora de novos debates no $b \log$, enquanto a informação direta deverá refletir a participação dos usuários e seus posicionamentos diante de determinada questão.

b) Opinativa. Quando trouxer na própria informação uma opinião a respeito de um fato, argumentada ou não, a mensagem será classificada como opinativa. Essa categoria poderá ser acumulada à informativa direta revelando a opinião do autor da mensagem sobre determinado tema ou fato discutido e poderá ser acumulada à categoria informativa indireta revelando a opinião de outra pessoa sobre algo. Em geral, uma mensagem que seja classificada como informativa indireta e opinativa terá um conteúdo argumentativo, buscando defender uma posição política na autoridade de um ator público, como forma de reforçar suas idéias.

c) Avaliativa crítica. Uma mensagem que tenha um ponto de vista argumentado a partir de uma cadeia lógica reflexiva, levantando hipóteses, avaliando argumentos, recuperando informações, será classificada como avaliativa crítica. Aqui notamos uma diferença entre as classificações críticas e opinativas pela qualidade e quantidade da argumentação sobre um acontecimento. Uma mensagem crítica deverá trazer à discussão elementos da ordem das razões capazes de fomentar novas reflexões e recuperar aspectos que poderiam ser perdidos se forem tomadas apenas as opiniões pessoais trazidas pelos internautas. Uma mensagem avaliativa crítica, portanto, revela um fim em si mesma quando propõe idéias buscando justificar-se pela argumentação.

d) Irônica. A mensagem será classificada dessa forma quando o autor revelar seu ponto de vista, pela escritura, usando o recurso da ironia. A 
ironia poderá ser usada como forma de convencimento, provocação ou encerramento de uma discussão e haverá a possibilidade de interpretação da informação por parte do leitor. Uma mensagem será classificada como irônica, portanto, se o pesquisador estiver atento aos fatos e à conjuntura a que se refere a informação e dependerá de uma interpretação subjetiva para que seu significado seja decodificado. A intenção de uma informação irônica nem sempre estará explícita e a comunicação entre o autor da mensagem e seus leitores será necessariamente múltipla, assim como as conseqüências dessa informação.

e) Posicionamento político. Mensagem na qual o conteúdo expressa um posicionamento político que conduz a lógica expositiva do argumento, possuindo elementos ideológicos e partidários. Assim, como o irônico, o posicionamento político do autor pode estar misturado à exposição de uma informação ou mesmo a uma análise. Nesse sentido, o pesquisador deve estar atento ao contexto político que cerca o conteúdo postado. Em muitos casos, esse recurso é utilizado como um elemento para firmar uma posição política comprometida com um compromisso político anterior.

f) Propositiva. Aqui o autor estará preocupado em encontrar soluções para um problema, ainda que haja a tentativa de evidenciar, como forma de argumentação, a ineficácia de uma ação que poderia ser diferente. Uma mensagem propositiva revela uma vontade por parte de seu autor, mas não revela a qualidade de sua proposta, sua viabilidade ou sua intencionalidade. Classificar uma mensagem como propositiva, no entanto, é reconhecer determinado tipo de ação política.

g) Avaliativa moral. Mensagem que reflete, além de uma opinião do autor, um julgamento moral. Essa categoria permite verificar em que medida os acontecimentos estão influenciando os humores dos internautas e revelam se os autores estão envolvidos emocionalmente com um acontecimento. Também é avaliativa moral uma mensagem que demonstre uma opinião dogmática e moralista e que tome essa forma de pensar como referência para uma conduta agressiva em uma discussão.

\section{III.4.2. Análise das imagens}

Também são analisadas e classificadas as imagens utilizadas nas mensagens. As imagens podem ser classificadas em cinco categorias: foto- grafia, animação, charge (desenho ou animação), figura e outros. As imagens também podem ser analisadas quanto à sua função em relação ao texto da mensagem, divididas em cinco categorias: (a) ilustrativa: quando a imagem é utilizada somente para ilustrar a mensagem; não oferecendo nenhuma informação complementar e possuindo uma função meramente decorativa; (b) crítica: quando a imagem tem uma função crítica, fazendo parte da informação junto ao texto da mensagem; (c) humor: quando a imagem tem a função de divertir o leitor ou ironizar um acontecimento que está sendo abordado; (d) informativa: quando a imagem traz consigo elementos informativos que ajudam na compreensão da mensagem e (e) outras.

\section{III.4.3. Hipertextualidade das mensagens}

Os links para outros sítios são importantes pois permitem que os usuários tenham acesso a outras informações, como também possibilita ao autor fazer referência a outros acontecimentos, indicar leituras e distintas fontes de informações por meio das conexões da rede de computadores. O número de links para outros blogs é um indicador de hipertextualidade, pois dentro da cultura dos blogs é muito comum os 'blogueiros' referenciarem-se, criando um debate que ultrapassa os limites do blog e envolve um amplo número de participantes.

\section{III.4.4. Temas abordados e comentários}

Também são monitorados os temas principais, os subtemas dos mensagens e o número de comentários que recebeu. Este estudo permite identificar a agenda do blog e verificar quais são os temas que despertam o maior número de comentários.

\section{III.5. Análise da interatividade}

No que diz respeito à interatividade do blog é importante ressaltar que essa nova forma de comunicação carrega em si a possibilidade de participação de diferentes indivíduos, ainda que se mantenham espacialmente distantes. O ciberespaço pode unir os diferentes atores políticos em uma ágora virtual em que as opiniões são filtradas pelos leitores e multiplicam-se em significados e conseqüências $^{18}$. Trata-se aqui não de examinar as possibilidades do meio de comunicação, mas

\footnotetext{
18 Sobre essa discussão teórica ver Araújo (2006).
} 
de criar ferramentas para buscar avaliar as possibilidades de participação que determinado blog oferece. Parte-se, portanto, do reconhecimento que a interação na internet é limitada, mas, dentro das possibilidades que o meio oferece, podem-se verificar as barreiras que são criadas para a participação e o incentivo feito pelo 'blogueiro' à interação com os internautas.

Para a análise da interatividade estuda-se os comentários publicados nos fóruns de debates dos blogs, utilizando as mesmas categorias de classificação dos mensagens (descritos anteriormente). Soma-se a elas a categoria dispersivo. Um comentário será dispersivo quando ignorar o tema em debate e escrever algo referindo-se a outra coisa, dando um novo rumo para a discussão ou dispersando-a. Será importante ao pesquisador observar se um comentário desviado não foi feito com uma intenção explícita de modificar a discussão ou se foi apenas um desvio aleatório que não interferiu no desenvolvimento do debate.

\section{RESULTADOS ALCANÇADOS}

Uma primeira proposta dessa metodologia foi apresentada no I Compolítica, realizado em Salvador em dezembro de 2006, e no Seminário Internacional El uso de las nuevas tecnologias em la campaña electoral brasileña de 2006, realizado em Madrid em janeiro de 2007. A partir de discussões e colaborações de outros pesquisadores foram incorporadas as modificações sugeridas e o método foi aplicado em uma pesquisa sobre a cobertura da eleição presidencial de 2006 na internet ${ }^{19}$. Ao estudar a atuação dos blogs de política nesse período, o método mostrou-se viável e de fácil utilização, alcançando interessantes resultados que foram apresentados no GT Democracia, Comunicação Política e Eleições, da Anpocs $^{20}$, em 2007.

Uma segunda aplicação do método foi apresentada no II Compolítica, realizado em Belo Horizonte em novembro de 2007. Os resultados obtidos confirmaram a utilidade dos procedimentos

19 Pesquisa de cooperação internacional entre Brasil e Espanha, coordenada pela professora Dra. Vera Chaia e pelo professor Victor Sampedro, financiada pela Capes (Coordenação de Aperfeiçoamento de Pessoal de Nível Superior). Mais informações, cf. Revista Aurora (2009).

20 Associação Nacional de Pós-Graduação e Pesquisa em Ciências Sociais. de pesquisa, bem como indicaram novos caminhos para futuras pesquisas sobre o tema que o grupo vem desenvolvendo. A seguir, apresentamos uma síntese dos resultados alcançados em duas pesquisas em que o método foi aplicado. A primeira tomou por base o período eleitoral de 2006 e três blogs de jornalistas com expressivo número de acessos. A segunda pesquisa analisou o debate em torno do movimento Cansei, em 2007, que fez uso das NTICs em sua organização e divulgação, influenciando, inclusive, a agenda da mídia tradicional. Para essa pesquisa foram selecionados três blogs de naturezas distintas; um blog independente, um jornalístico e outro político.

IV.1. Internet e politica: os blogs nas eleições presidenciais de 2006 21

Foram selecionados os blogs dos jornalistas Ricardo Noblat, Josias de Souza e Luis Nassif. A escolha de blogs de jornalistas da mídia tradicional deveu-se ao elevado número de acessos a essas páginas, o que permitiria aos pesquisadores, durante a análise da cobertura das eleições, avaliar o impacto dos blogs na formação da opinião pública. Foram aplicados os cinco procedimentos metodológicos aqui descritos e os resultados da análise foram sistematizados e apresentados a seguir.

O blog de Josias de Souza, "Nos Bastidores do Poder" (SOUZA, 2009) nasceu no dia 15 de outubro de 2005, em um período agitado pelas denúncias envolvendo o pagamento aos deputados da base aliada ao governo Lula em troca de apoio político ("mensalão"). As denúncias envolviam diretamente a alta cúpula petista do governo federal, agitando os noticiários e a vida política brasileira envolta em mais um escândalo político. Na primeira mensagem escrita pelo jornalista, com o título "termo de compromisso", Josias tenta definir o funcionamento do blog e sua forma de cobertura sobre os eventos políticos a partir de um conjunto de compromissos assumidos com os leitores. O "termo de compromisso" está baseado em sua "experiência de repórter e na cultura editorial" do jornal Folha de S. Paulo, dispostos em sete tópicos. Os tópicos indicam o posicionamento de Josias de Souza típico do estilo jornalístico adotado pelos grandes jornais bra-

21 Uma versão completa da análise da cobertura das eleições presidenciais de 2006 feita nos blogs foi apresentada em Penteado, Santos e Araújo (2007b). 
sileiros. Apesar de utilizar um formato mais ágil, típico do blog de política, o jornalista indica que seguirá os modelos tradicionais do jornalismo, reconhecendo algumas características do "universo da informação em tempo real" como o erro e a imprecisão das informações e a possibilidade de interação com os leitores.

O "Blog do Noblat" (NOBLAT, 2009) nasceu na noite do dia 20 de março de 2004 com uma única mensagem: "Bem-vindos ao meu Blog". No dia seguinte, outras duas mensagens, uma em agradecimento pelas primeiras mensagens recebidas e outra comentando o desempenho do governo Lula, de forma breve, em relação a uma das mensagens recebidas. O blog surge como uma atividade paralela à do jornalista, que estava em Brasília acompanhando os fatos do governo Lula, e coincide com o período subseqüente ao escândalo causado pelo caso Waldomiro Diniz, que recebe rápida menção em uma mensagem no terceiro dia de existência do blog. O estilo do Blog do Noblat aparece ao leitor como uma fonte menos controlada da informação, notadamente pela divulgação de notícias de última hora escritas de maneira, às vezes, bastante informal. $\mathrm{O}$ próprio Noblat escreve: "Minha pretensão é de atualizar esse blog diariamente. Se tiver notícias que não possa, não deva ou não queira guardar para o domingo, elas serão adiantadas aqui". O blog surge como o lugar certo para se encontrar informações que poderiam ser censuradas pelos meios tradicionais de comunicação.

O blog "Luis Nassif Online" (NASSIF, 2009) surge no dia 30 de maio de 2006, durante o período que antecedeu o início da campanha oficial das eleições de 2006; um momento de intensa agitação política, principalmente nas coberturas jornalísticas dos pré-candidatos. $\mathrm{Na}$ mensagem inicial do blog, o jornalista explica os motivos de sua criação e como ele vai funcionar. Em relação aos motivos, Nassif assinala que após algum tempo de resistência resolveu aderir aos blogs, acreditando tratar-se do futuro do jornalismo na internet, um meio de realizar interações com seus leitores, além de ser um espaço para escrever suas crônicas, uma de suas paixões da juventude. $O$ jornalista explica que o blog está dividido em quatro categorias: o Blog, Crônicas, Minhas Músicas e Livros, sendo essa última substituída por Economia.

Os três blogs estudados são escritos por jornalistas, o que confere um perfil informativo aos mesmos. Como estão vinculados a portais de grande visibilidade; empresas de mídia tradicional como O Globo, do Blog do Noblat, e Folha Online, do blog de Josias, e um grande portal de internet, o IG, do blog de Nassif; os blogs têm um número grande de acessos além de significativa credibilidade, também atribuída aos autores e seus históricos profissionais.

No que diz respeito à estrutura dos blogs, foi verificado que o Blog do Noblat é mais completo que os demais, possuindo maior participação de colaboradores, uma forma a mais de interação (seção Desabafo), uma bibliografia mais completa e um número maior de seções e serviços para os usuários. Os três blogs têm mensagem diária de textos e mantêm links externos e internos. Nos blogs de Josias e de Nassif, a biografia é parcial e a interação dos usuários ocorre por meio dos fóruns de discussão e por e-mail. O blog de Nassif destaca-se pelo espaço destinado aos vídeos de músicos e às suas crônicas.

As mensagens foram lidas e analisadas pelos pesquisadores e classificados de acordo com as categorias criadas.

\section{QUADRO 1-CLASSIFICAÇÃO DAS MENSAGENS (\%)}

\begin{tabular}{|l|c|c|c|}
\hline Classificação & Josias & Noblat & Nassif \\
\hline informativo direto & 30 & 26,7 & 16,7 \\
informativo indireto & 66,7 & 63,3 & 16,7 \\
avaliativo-crítico & 33,3 & 50 & 60 \\
propositivo & 0 & 0 & 0 \\
Irônico & 26,7 & 10 & 16,7 \\
avaliativo-moral & 6,7 & 0 & 3,3 \\
opinativo & 20 & 26,7 & 60 \\
posicionamento político & 10 & 3,3 & 0 \\
\hline
\end{tabular}

FONTE: Elaboração dos autores.

NOTA: As porcentagens têm por base a totalidade de ocorrências da amostra e sua somatória excede $100 \%$ pelo fato de ser possível o acúmulo de mais de um enquadramento para o mesmo texto. 
De forma geral, durante a cobertura das eleições em 2006, ocorreu uma maior incidência de mensagens informativas indiretas nos blogs de Noblat e de Josias, que na maioria das vezes eram textos já publicados na mídia tradicional. O blog do Nassif destacou-se pelos textos avaliativos críticos e opinativos, dando-o uma pessoalidade maior. Vale destacar ainda que não foram verificadas mensagens avaliativas morais no blog de Noblat, e, nos demais, um número inexpressivo, o que indica que os autores procuram reproduzir nos blogs o estilo de escrita do jornalismo tradicional. Nenhuma mensagem analisada pôde ser enquadrada como propositiva.

Dos três blogs analisados, o do Josias é o que mais apresenta mensagens com ocorrência de imagens, na maioria das vezes $(60 \%)$ fotos, com a função de ilustração dos textos, mas também fi- guras e animações. Josias utilizou imagens em todos os seus mensagens, ao contrário do Noblat, que dificilmente utiliza imagens em seus mensagens. As imagens do Blog do Noblat, quando aparecem, são fotos classificadas como "imagem do dia”. O Blog do Nassif não apresenta imagens, exceto as imagens dos vídeos sobre músicas, publicados em alguns mensagens sobre esse tema.

Quanto à hipertextualidade, observamos que Josias de Souza e Ricardo Noblat utilizaram bastante esse recurso, enquanto Luis Nassif usou muito pouco. No blog de Josias, muitos dos links existentes estavam direcionados para reportagens do jornal Folha de S. Paulo, local em que o blog está hospedado, limitando o alcance da hipertextualidade. Por outro lado, Noblat chegou a fazer referência a outros blogs, por meio de links, característica muito comum da blogosfera.

\section{QUADRO 2 - TEMAS (\%)}

\begin{tabular}{|lcccc|}
\hline Temas & Nassif & Noblat & Josias \\
\hline ec onomia e política econômica & 20 & 0 & 6,7 \\
infra-estrutura & 0 & 0 & 0 \\
Social & 3,3 & 0 & 0 \\
violência e segurança & 0 & 3,3 & 3,3 \\
ciência, tecnologia e cultura & 0 & 0 & 0 \\
campanha eleitoral & 53,3 & 56,7 & 66,7 \\
Candidatos & 13,3 & 20 & 10 \\
contendas políticas & 10 & 20 & 10 \\
política extema & 0 & 0 & 0 \\
Outros & 0 & 0 & 3,3 \\
\hline
\end{tabular}

FONTE: Elaboração dos autores.

Ao avaliar a incidência dos temas de política, a maioria dos textos era voltada para os temas de campanha eleitoral, conforme esperado inicialmente, com algumas mensagens tratando de contendas entre candidatos. Destaca-se o significativo número de mensagens de Luis Nassif dedicado aos temas econômicos, o que condiz com o histórico e formação do autor. Vale notar, no Quadro 2, a homogeneidade de temas entre os três blogs.

\section{QUADRO 3-CLASSIFICAÇÃO DOS COMENTÁRIOS DOS MENSAGENS (\%)}

\begin{tabular}{|l|c|c|c|}
\hline Classificação & Josias & Noblat & Nassif \\
\hline informativo direto & 3,5 & 3,5 & 2,1 \\
informativo indireto & 8 & 3,5 & 4,1 \\
avaliativo crítico & 3,5 & 7,1 & 11,8 \\
Propositivo & 3 & 0,5 & 1,5 \\
Irônico & 25,5 & 37,4 & 12,3 \\
avaliativo moral & 38 & 20,2 & 17,4 \\
Opinativo & 14 & 33,3 & 44,6 \\
posicionamento político & 48 & 25,8 & 17,9 \\
Dispersivo & 53 & 40 & 25,6 \\
\hline
\end{tabular}

FONTE: Elaboração dos autores. 
O Quadro 3 mostra que, nos fóruns de comentários, foi constatado um grande número de mensagens dispersivas, especialmente nos blogs de Josias e de Noblat, o que indica uma perda da qualidade do debate político. Outro indicador nesse sentido é o grande número de ocorrências de comentários avaliativos morais. Vale destacar o expressivo índice de comentários publicados no blog de Josias que indica um posicionamento político do usuário e o baixo índice de textos propositivos. Ficou constatado, também, que nos comentários não há um número expressivo de textos informativos, o que implica reconhecer que os usuários reagem às mensagens e tecem opiniões, mas não se preocupam em trazer novos dados para o debate.

Os resultados alcançados indicam que o blog de Noblat tem características mais próximas ao formato original dos blogs (diários pessoais): músicas, poemas, vídeos e uma seção para o "desabafo" do usuário. Noblat estrutura seus mensagens, em sua maioria, a partir de informações coletadas em outras fontes, e serve-se de uma rede de colaboradores. Esse tipo de atuação faz que o conteúdo de seus mensagens tenha um caráter mais informativo e de análise crítica. Nesse blog pode-se perceber que há uma mistura entre o público e o privado, uma vez que a maioria das mensagens tem um caráter público, trazendo informações, análises e opiniões, ao mesmo tempo em que o próprio Noblat utiliza esse espaço para compartilhar e expor suas preferências musicais e artísticas pessoais. Na seção desabafo, também notamos a expressão pública de sentimentos e opiniões pessoais dos usuários.

Josias de Souza, em seu blog, segue a linha jornalística, trazendo diversas informações a partir de fontes oficiais, pessoais e de contatos que possui. A análise das mensagens sinaliza que o principal enquadramento adotado por Josias é de caráter informativo, no entanto, ele também faz algumas análises de caráter crítico, avaliativo e irônico, diferentemente do observado no blog de Noblat. O blog também se caracteriza por apresentar algumas seções distintas, mas sem um caráter de pessoalidade como ocorre no blog de Noblat. Outro elemento importante é o uso recorrente de imagens nas mensagens e referências a outras reportagens da Folha de S. Paulo. Ao contrário do verificado no blog do Noblat, no blog de
Josias os elementos privados ficam restritos à apresentação de opiniões e análises, não existindo uma interatividade personalista entre o titular do blog e seus usuários.

No Luis Nassif Online, observamos uma estrutura de serviços mais simples do que as encontradas anteriormente. O blog apresenta menos serviços para os usuários e está dividido em áreas de interesse do autor: blog, economia, minhas músicas e crônicas. Nassif apropria-se da ferramenta de forma a expressar suas opiniões políticas e econômicas, bem como exercitar suas áreas de interesse pessoal (músicas e crônicas). $\mathrm{Na}$ área de política e economia vemos uma grande preocupação em não somente informar, mas também apresentar suas análises e suscitar um debate com seus leitores. Em diversos momentos registramos o autor questionando-os para emitir suas opiniões e estimular o debate. Percebemos a preocupação do autor em fazer do seu blog um espaço compartilhado com seus leitores, indo além da simples apresentação de novas informações.

A respeito dos temas abordados, vale frisar que os três blogs voltaram sua atenção para a campanha eleitoral, os candidatos e as contendas políticas que marcaram o período. Percebemos uma ênfase no tratamento do processo eleitoral, o que significou o abandono de temas tradicionais como infra-estrutura, política externa, cultura, tecnologia, segurança e outros temas sociais.

Sobre a interatividade, por meio da análise dos comentários das mensagens, foi verificada a existência de um debate entre os leitores em todos os blogs estudados. Contudo, os debates desses fóruns caracterizam-se pela falta de qualidade dos argumentos, com a exceção do blog de Nassif, no qual notamos existir uma maior preocupação do próprio autor com o estímulo ao debate, inclusive com a participação do titular respondendo a alguns dos textos. Os comentários estudados no blog de Nassif caracterizaram-se por serem mais extensos e pelo maior cuidado na articulação das idéias, mas verificamos que o número de acessos a esse blog é bem menor que o dos outros dois casos estudados. Nestes, verificou-se que, apesar de haver posicionamento político dos comentadores e o conseqüente debate em torno desses posicionamentos, uma parte significativa dos comentários fugiu ao tema da mensagem de 
referência, ou então foram feitos comentários de avaliação moral, não se preocupando em apresentar propostas ou tecer comentários com análises críticas, gerando um debate de conteúdo estéril para a promoção da democracia.

\section{IV.2. O movimento cansei: o debate na blogosfera ${ }^{22}$}

Foi feita uma investigação, por meio do método proposto, sobre o debate realizado pelos blogs de política a respeito do movimento Cansei. Para a realização desse estudo, foram selecionados três perfis de autores de blogs com características diferentes: Noblat (jornalista), Nariz Gelado (independente) e Zé Dirceu (político). O objetivo da pesquisa foi verificar, além do debate político na blogosfera, a diferença de abordagem de acordo com o perfil do 'blogueiro', buscando avaliar os estilos, perspectivas e formatos de blogs cujos autores possuem perfis diferenciados.

O movimento Cansei (Movimento Cívico pelo Direito dos Brasileiros) surge logo após o acidente com o avião da TAM, em 17 de julho de 200723, que constituiu a maior tragédia da aviação brasileira. Um grupo de empresários e personalidades públicas, liderados pelo presidente da Phillips do Brasil, Paulo Zottolo, pelo presidente da OAB$\mathrm{SP}^{24}$, Luiz Flávio Borges D’Urso, e pelo empresário do entretenimento João Dória Júnior, propôs um movimento de contestação e manifestação da sociedade brasileira, tecendo críticas aos políticos em geral.

O movimento apresentava-se como apartidário, embora alguns de seus idealizadores tivessem identificação - ou proximidade - com o $\mathrm{PSDB}^{25}$. De acordo com seus propositores, o Cansei tinha por intenção levantar discussões e bandeiras contra o caos aéreo, a corrupção, a violência, as crianças nas ruas, os impostos abusivos e outras mazelas que atingem a sociedade brasileira. As críticas, embora fossem aos políticos em geral, estavam mais voltadas ao Governo Federal.

\footnotetext{
22 Uma versão completa da análise do Movimento Cansei foi apresentada em Penteado, Santos e Araújo (2007c).

23 O acidente ocorreu em 17 de julho de 2007, e foi depois dessa data que o movimento ganhou espaço nas mídias tradicionais e "virtuais".

24 Ordem dos Advogados do Brasil, São Paulo.

25 Partido Social-Democrata Brasileiro.
}

O Cansei fez uso da mídia tradicional, mas também se articulou por meio das NTICs, com um blog na internet ${ }^{26}$, por meio de comunidades no Orkut, e também com vídeos de propaganda no Youtube, ou seja, foram utilizados vários meios para tentar mobilizar o maior número possível de pessoas. O movimento dizia-se apoiado por mais de 60 entidades de classe, o que possibilitou encará-lo como uma forma significativa de ação política.

Desde o seu surgimento o Cansei causou polêmica. Muitas pessoas reprovaram o fato do movimento ter surgido em plena crise aérea no país e, mais especificamente, após o acidente da TAM. Por isso, foi classificado por alguns como oportunista. Além do fato de alguns de seus criadores e propagandistas serem notórios críticos do governo Lula e pró-PSDB. Na OAB, inclusive, houve um grupo liderado pela seccional do Rio de Janeiro que se recusou a participar e a aderir ao movimento, colocando-se criticamente contra a sua organização.

Analisamos a forma com que os três blogs selecionados cobriram o movimento, avaliando qualitativamente os mensagens e comentários, mas também o perfil dos 'blogueiros', a estrutura e o histórico dos blogs.

O blog de jornalista escolhido para essa pesquisa foi o de Noblat, cujas características foram descritas anteriormente. Como blog de político, selecionamos o de Zé Dirceu (DIRCEU, 2009), e como blog independente o de Nariz Gelado (BLOG NARIZ GELADO, 2009).

O blog Nariz Gelado teve início em março de 2003 e, como a própria autora disse ${ }^{27}$, trata-se de um espaço no qual ela faz uma "egotrip", escrevendo seus pensamentos sobre política, cultura e sociedade. É independente, pois não está vinculado a nenhuma instituição da mídia tradicional, mas faz parte da comunidade de blogs Apostos ${ }^{28}$. Segundo a autora, trata-se de uma atividade não re-

26 O endereço oficial do movimento foi http:// blog.cansei.com.br/. Atualmente (20.jul.2009), o blog está desativado.

27 Correspondência eletrônica com a autora. Resposta em 11 de outubro de 2007.

28 Disponível em http://www.apostos.com; acesso em 20.jul.2009. 
munerada que ganhou projeção a partir da citação por parte de alguns veículos da imprensa (Folha de S. Paulo, Blog do Noblat ${ }^{29}$, Observatório da Imprensa, além do Programa do Jô) e o aumento do público que busca informações políticas por meio de blogs, principalmente após os escândalos políticos ocorridos a partir de 2005 no país. A 'blogueira' 30 considera seu posicionamento político como sendo de centro-direita. Possui uma visão crítica frente à atuação dos partidos políticos, não se alinhando com nenhum deles. Em relação ao Cansei, apesar de ser contra o governo Lula, foi crítica em relação aos objetivos e à eficácia do movimento, postando comentários desfavoráveis a ele. Afirma ter uma preocupação ética, ao evitar a divulgação de coisas que ainda não foram publicadas na imprensa.

O blog de Zé Dirceu, escrito pelo ex-Ministro da Casa Civil, tem menos serviços do que outros que tratam de política e também está associado a um grande portal de internet. A trajetória política de José Dirceu é conhecida e associa-se à fundação do Partido dos Trabalhadores, além dos escândalos políticos divulgados no período em que ocupava o cargo de Ministro. As informações sobre o histórico do blog, no entanto, não foram encontradas.

Quanto à localização, o blog de Noblat encontra-se hospedado no sítio do portal do jornal O Glo- bo, o que lhe garante credibilidade e visibilidade. $\mathrm{O}$ mesmo ocorre com o blog do Zé Dirceu, que está hospedado no IG, um dos maiores portais brasileiros. O blog Nariz Gelado é independente e não está associado a nenhuma empresa de mídia, o que diminui sua credibilidade e número de acessos.

$\mathrm{Na}$ análise da estrutura dos $b \log s$, obervou-se que o blog de Noblat é o mais completo, possuindo um maior números de mensagens diários, assim como uma rede de colaboradores assíduos. Assim como apontado na pesquisa anterior, o blog de Noblat oferece outra alternativa para a interatividade, a seção "Desabafe", e apresenta uma biografia mais completa que a dos demais, como também oferece mais serviços aos usuários. O Nariz Gelado caracteriza-se por uma estrutura simples, comum aos blogs independentes, e o blog de Zé Dirceu, também simples, acaba por ser um serviço do sítio do próprio político.

Quanto ao enquadramento das mensagens, o Quadro 4 indica que houve maior ocorrência de mensagens informativas indiretas. No Nariz Gelado também se pode destacar a utilização de textos críticos e avaliativo-morais. Outro destaque fica para o blog de Zé Dirceu, com o uso de mensagens críticas em vez de mensagens com posicionamento político, como esperado inicialmente. O Quadro 5 apresenta a incidência dos enquadramentos nas mensagens analisados.

QUADRO 4 - ENQUADRAMENTO DAS MENSAGENS (\%)

\begin{tabular}{|l|c|c|c|}
\hline classificação & Nariz Gelado & Noblat & Zé Dirceu \\
\hline infomativo direto & 25 & 6,3 & 0 \\
infomativo indireto & 50 & 50 & 100 \\
opinativo & 25 & 18,8 & 25 \\
análise crítica & 37,5 & 25 & 75 \\
irônico & 25 & 18,8 & 0 \\
posic ionamento político & 0 & 0 & 0 \\
propositivo & 12,5 & 0 & 0 \\
avaliativo moral & 37,5 & 12,5 & 0 \\
\hline
\end{tabular}

FONTE: Elaboração dos autores.

\footnotetext{
29 Foram observados, nos comentários do Noblat durante a pesquisa, referências ao blog de Nariz Gelado.

30 A autora permanece anônima. O uso de pseudônimo está ligado a uma cultura própria dos 'blogueiros'. Há, no blog, o seguinte texto de apresentação: "Quando a geada
}

ameaça a planície, este meu arrebitado nariz congela. A geada é minha razão de ser. A História é meu escudo e minha lança. À espera de um longo e rigoroso inverno, escrevo. Eu sou Nariz Gelado" (BLOG NARIZ GELADO, 2009) 
Em relação à hipertextualidade dos $b \log s$ estudados, o blog Nariz Gelado utilizou mais esse recurso, característica da blogosfera independente, inclusive com links para outros blogs. Zé Dirceu deu pouco destaque, em seu blog, ao movimento Cansei, as poucas mensagens publicados faziam referência a uma fonte de informação indireta. Esse recurso pode ter sido usado pelo autor para dar credibilidade a seus comentários. Ainda que tenham sido poucas mensagens, o número de comentários dos usuários foi significativo.

Durante o período de 46 dias $^{31}$ em que os três blogs foram monitorados, foram postados 28 textos sobre o movimento Cansei, dos quais 16 foram do blog de Noblat, oito no Nariz Gelado e quatro no Zé Dirceu. Das 16 mensagens publicadas por Noblat, apenas uma trouxe um link para outro blog; no Nariz Gelado, no entanto, cinco mensagens faziam referência a outros blogs. Essa é uma das características que diferencia o blog independente dos demais.

Quanto à interação dos usuários, o debate nos fóruns ficou marcado pela expressão de opiniões pessoais sobre o assunto, sem a apresentação de argumentos que sustentassem as opiniões. Outro dado interessante diz respeito à presença de comentários indicativos de posicionamentos políticos no Nariz Gelado, além de comentários avaliativos morais nos blogs de Noblat e Zé Dirceu. Abaixo, no Quadro 5, os enquadramentos dos comentários analisados estão sistematizados.

\section{QUADRO 5 - INTERATIVIDADE (\%)}

\begin{tabular}{|l|c|c|c|}
\hline Classificação & Nariz Gelado & Noblat & Zé Dircea \\
\hline infomativo direto & 7 & 0 & 2,5 \\
infomativo indireto & 7 & 1,9 & 7,5 \\
opinativo & 42,1 & 31,3 & 32,5 \\
análise crítica & 5,3 & 5 & 17,5 \\
irônico & 17,5 & 23,8 & 10 \\
posic ionamento político & 35,1 & 16,3 & 22,5 \\
propositivo & 1,8 & 0 & 5 \\
avaliativo moral & 22,8 & 38,1 & 35 \\
dispersivo & 8,8 & 15,6 & 15 \\
\hline
\end{tabular}

FONTE: Elaboração dos autores.

Na cobertura do Cansei, o blog de Noblat procurou manter uma posição mais neutra, apresentando uma abordagem mais informativa em relação ao movimento, como também postando textos de colaboradores favoráveis e desfavoráveis. Zé Dirceu, ao contrário do esperado inicialmente, deu pouca atenção ao Cansei, somente postando quatro textos. As mensagens de Dirceu caracterizaram-se pelo seu aspecto informativo e pelo desenvolvimento de análises críticas, evitando fazer avaliações morais sobre o tema. Por fim, o blog independente Nariz Gelado caracterizou-se pelas avaliações morais e pela tentativa de criticar o movimento, propondo outras linhas de ação contra o "caos aéreo" e contra a disseminação de boatos.

A blogosfera também permite a criação de novos espaços de debate político. O estudo dos co-

\footnotetext{
31 O período selecionado para a análise foi de 17 de julho
} a 31 de agosto de 2007 . mentários permitiu observar como pensa uma parcela da população ${ }^{32}$ sobre alguns dos temas políticos. No que diz respeito ao Cansei, foi observado que o movimento provocou uma grande polêmica entre os comentaristas, despertando paixões e posicionamentos políticos polarizados.

As discussões no blog de Noblat foram marcadas, predominantemente, por comentários com avaliações morais e emissão de opiniões pessoais, havendo pouca ocorrência de análises críticas e nenhuma proposição. Talvez por ter adotado uma postura mais neutra em relação ao movimento, seu fórum de debate foi o mais tenso, pois atraia pessoas favoráveis e contrárias ao movimento, com troca de ofensas e acusações entre elas. O blog de Zé Dirceu caracterizou-se pela maior ocorrência de comentários alinhados à po32 Essa parcela da população é formada por pessoas com
acesso à internet e com interesse em política. 
sição política do autor, mas predominando avaliações morais e opiniões contrárias ao movimento, havendo pouco debate de posições diferentes. Os comentários com a emissão de opiniões e posicionamentos políticos são predominantes no blog Nariz Gelado. Neste, observou-se um conflito entre críticas ao movimento e moções de apoio, inclusive com a participação da 'blogueira'.

De maneira geral, foi constatado que, apesar de haver debate político dos comentadores, a maioria dos comentários fugiu ao tema da mensagem de referência, ou então, foram avaliativomorais, não se preocupando em apresentar propostas ou tecer reflexões com análises críticas, gerando um debate de conteúdo frágil que pouco contribui para o civismo. Isso demonstra que apesar de serem novos espaços para a promoção da democracia, os blogs em si mesmos não garantem a formação de um debate profícuo, pelo qual os participantes procuram apresentar argumentos e fatos que comprovem suas posições; pelo contrário, os fóruns, em geral, transformam-se em espaços de expressão de sentimentos pessoais, descontentes com a vida política brasileira, e caracterizados pelo senso comum.

Ao final da pesquisa, após a análise dos resultados obtidos, ficou confirmado que o perfil do 'blogueiro' influencia o formato da cobertura dos acontecimentos políticos e mesmo o debate político que acontece nos fóruns. O jornalista Ricardo Noblat possui um maior destaque e credibilidade, o que lhe garante um número maior de leitores. Zé Dirceu tem leitores alinhados à sua trajetória política, enquanto que Nariz Gelado atua dentro de uma rede de relações construídas pela própria blogosfera, atraindo pessoas que possuem o mesmo alinhamento político e que pertençam à sua rede social.

\section{CONCLUSÕES}

Procuramos apresentar e descrever um método de investigação científica de blogs de política, assim como alguns dos resultados alcançados por meio dessa ferramenta de pesquisa.

Cabe lembrar que a metodologia apresentada é composta pela aplicação de cinco técnicas de investigação, assim, recomenda-se que no estudo de blogs de política seja utilizado o método completo a fim de evitar a descontextualização do objeto ou uma análise insuficiente. Ainda assim, pode haver estudos em que sejam feitas novas combi- nações de métodos, selecionando dentre as técnicas propostas as que melhor ajustam-se ao objetivo de pesquisa.

A metodologia exposta neste artigo procura seguir o alerta de Thiollent (1982) em relação às técnicas de pesquisas, que, segundo o autor, caracterizam-se pelo (1) caráter anti-histórico dos procedimentos que não problematizam o contexto no qual as informações são obtidas; (2) pela crítica à concepção empirista que concebe os dados por si mesmos, como geradores de conceitos e de explicações, manifestando uma percepção positivista da realidade social; (3) pela profissionalização dos pesquisadores (defesa do corporativismo e da fixação de técnicas de pesquisa para competir no mercado de trabalho), fato que inibe as inovações e (4) pelo teoricismo de alguns cientistas, que rejeitam qualquer tipo de técnica de pesquisa.

Dessa maneira, é importante destacar que o método aqui sugerido não tem o caráter explicativo, mas funciona como uma técnica de coleta de dados (leitura) dos blogs de política. As informações obtidas devem ser analisadas dentro de um referencial teórico mais amplo que caracterize a pesquisa. Assim, acreditamos que evite tanto o empirismo como o teoricismo, adotando uma abordagem metodológica inovadora que privilegia os aspectos técnicos e teóricos que orientam a investigação.

Para resolver o problema do caráter anti-histórico dos procedimentos de pesquisa, a própria metodologia propõe uma análise históricocontextual do blog, contendo um breve histórico do blog, a biografia do 'blogueiro' e uma análise sócio-política do contexto em que o blog está inserido. Essa análise histórico-contextual permite que os dados coletados sejam analisados à luz das redes de significado de um determinado momento histórico.

Como verificado nos resultados apresentados acima, a metodologia mostrou-se confiável e eficiente, demonstrando ser uma ferramenta eficaz de pesquisa para a realização de novas investigações sobre os blogs de política. Por fim, é importante chamar a atenção para as inovações que os blogs trazem para a ação política na sociedade da informação, fato que suscita novos temas de pesquisa para os pesquisadores das áreas de Ciências Sociais, Comunicação Social, Cibercultra e Ciências da Informação. 
Cláudio Luis de Camargo Penteado (claudio.penteado@ufabc.edu.br) é Doutor em Ciências Sociais pela Pontifícia Universidade Católica de São Paulo e Professor da Universidade Federal do ABC.

Marcelo Burgos Pimentel dos Santos (marceloburgos@uol.com.br) é Doutorando em Ciências Sociais pela Pontifícia Universidade Católica de São Paulo.

Rafael de Paula Aguiar Araújo (rafa77@uol.com.br) é Doutor em Ciências Sociais pela Pontifícia Universidade Católica de São Paulo e Professor da Pontifícia Universidade Católica de São Paulo e da Escola de Sociologia e Política (ESP).

\section{REFERÊNCIAS BIBLIOGRÁFICAS}

ALDÉ, A. \& CHAGAS, V. 2005. Blog de política e identidade jornalística. In : ENCONTRO DOS NÚCLEOS DE PESQUISA DA INTERCOM, 5., Rio de Janeiro. Anais..., v. 1. Rio de Janeiro : Intercom.

ALDÉ, A.; ESCOBAR, J. \& CHAGAS, V. 2006. A febre dos blogs de política. In : ENCONTROANUAL DA COMPÓS, 15., 2006, 6-9.jun, Bauru. Anais... Bauru : Compós. Disponível em : http:// www.faac.unesp.br/compos $2006 /$ imprimirGT02.htm Acesso em : 2.jul.2009.

ARAÚJO, R. 2006. Mídia eletrônica e a convulsão do tempo social. In : CONGRESSO LATINO-AMERICANO DE CIÊNCIA POLÍTICA, 3., Campinas. Anais... Campinas : UNICAMP.

BRAGA, S. 2006. Internet e política : um estudo sobre a informatização dos orgãos legislativos na América do Sul. In:CONGRESSO LATINO-AMERICANO DE CIÊNCIA POLÍTICA, 3., Campinas. Anais... Campinas : UNICAMP.

CASTELLS, M. 1999a. Sociedade em rede. São Paulo : Paz e Terra.

1999b. O poder da identidade. São Paulo : Paz e Terra.

CHAIA, V. M. (coord.). 2006. Projeto Temático : Mídia, Campanha Eleitoral e Comportamento Político em São Paulo nas eleições de 2000 e 2004. São Paulo : PUC-SP. Disponível em : http://www.pucsp.br/ neamp Acesso em : 2.jul.2009.

DIRCEU, Z. Zé Dirceu. Um espaço para a discussão do Brasil. Sítio de internet de José Dirceu. Disponível em : http://www.zedirceu.com.br Acesso em :22.jul.2009.

GILL, K. 2004. How Can We Measure the Influence of the Blogosphere? In :WWW2004, Nova York, 2004, 17-22.May. New York : Workshop on the Weblogging Ecosystem. Disponível em : http:// faculty.washington.edu/kegill/pub/ www2004_blogosphere_gill.pdf Acesso em : 2.jul.2009.
KAHN, R. \& KELLNER, D. 2004. New Media and Internet Activism : from the "Battle of Seattle" to Blogging. New Media \& Society. Disponível em: http://nms.sagepub.com/cgi/reprint/6/1/87.pdf

LANDTSHEER, C. \& NEUNER, N. 2000. La facilidad de utilización de los "web sítios" de partidos políticos. Estudio de algunos países de Europ del Este y Occidental. Cuadernos de Información y Comunicación, Madrid, n. 6.

LEMOS, A.; MAMEDE, J.; NÓBREGA, R.; PEREIRA, S. \& MEIRELLES, L. 2004. Cidade, tecnologia e interfaces. Análise de interfaces de portais governamentais brasileiros. Uma proposta metodológica. Revista Fronteiras, São Leopoldo, v. 6, n. 2. Disponível em : http:// revcom2.portcom.intercom.org.br/index.php/fronteiras/article/view/3096/2906 Acesso em : 20.jul.2009.

NASSIF, L. 2009. Luis Nassifonline. Blog do jornalista Luis Nassif. Disponível em http:// colunistas.ig.com.br/luisnassif/ Acesso em : 20.jul.2009.

NOBLAT, R. 2009. Blog do Noblat. Blog do jornalista Ricardo Noblat. Rio de Janeiro : O Globo. Disponível em : http://oglobo.globo.com/pais/noblat/ Acesso em : 20.jul.2009.

MONTARDO, S. P.;AMARAL,A. \& RECUERO, R. C. (orgs.). 2009. Blogs.com : estudos sobre blogs e comunicação. São Paulo : Momento.

NICOLAS, M. M.; MADRIAGA, J. M. G \& TUCHO, F. 2004. Redes con lastre. El periodismo digital ante la transformación de la comunicación política electoral. In: OTERO, M. L. et alii. (eds.). Cara a novos espazos ciberxornalísticos. Actas do II Congresso Iberoamericano de Jornalismo Digital. Santiago de Compostela : Universidad de Santiago de Compostela, p. 167-192.

2005. Democracia digital : nuevos medios y participación ciudadana. Experiencias en la red 
de la población inmigrante en España, Portularia. Revista de Trabajo Social, v. 6, p. 7-20.

PENTEADO, C. L. C., SANTOS, M. B. P. \& ARAUJO, R. P. A. 2006. Blogs de política : caminhos para a reflexão. In : COMPOLÍTICA, 1., Salvador. Anais... Salvador : Associação Brasileira de Pesquisadores de Comunicação e Política. Disponível em : http://www.fafich.ufmg.br/compolitica/ anais2006/Penteado_Santos_e_Araujo_2006.pdf Acesso em : 20.jul.2009.

2007a. Blogs e eleições presidenciais em 2006. In : CONGRESSO BRASILEIRO DE SOCIOLOGIA, 13., Recife. Anais... Recife : Sociedade Brasileira de Sociologia.

.2007b. Internet e Politica : os blogs nas eleições presidenciais 2006. In : ENCONTRO ANUALDAANPOCS, 31., Caxambu. Anais... Caxambu :ANPOCS.

.2007c. O movimento "cansei" na blogosfera : o debate nos blogs de política. In : COMPOLÍTICA, 2., Belo Horizonte. Anais... Belo Horizonte : Associação Brasileira de Pesquisadores de Comunicação e Política. Disponível em: http://www.fafich.ufmg.br/compolitica/anais2007/ gt_ip-rafael.pdf Acesso em : 20.jul.2009.

2008. Blogs e ação política na internet. In : SIMPÓSIO DAASSOCIAÇÃO BRASILEIRADE CIBERCULTURA, 2., São Paulo. Anais... São Paulo : Associação Brasileira de Cibercultura. Dispo- nível em : http://www.cencib.org/simposioabciber/ $\mathrm{PDFs} / \mathrm{CC} /$ Claudio\%20Luis\%20de\%20Camargo\% 20Penteado, \% 20Marcelo\%20Burgos $\% 20$ Pimentel\%20d os\%20Santos\%20e\%20Rafael\% 20de\%20Paula\% 20Aguiar\%20Araujo.pdf Acesso em: 20.jul.2009.

PORTO, M. 1999. A Crise de Confiança na Política e suas Instituições : os mídia e a legitimidade da democracia. In : ENCONTRO NACIONAL DA ANPOCS, 22., Caxambu. Anais... Caxambu : ANPOCS.

2002. Enquadramento de Mídia e Política. In: CONGRESSO BRASILEIRO DE CIÊNCIAS DACOMUNICAÇÃO, 25., Salvador. Anais... Salvador : Intercom.

RECUERO, R. 2003. Weblogs, webrings e comunidades virtuais. 404nOtF0und, v. 1, n. 31. Disponível em: http://facom.ufba.br/ciberpesquisa/ 404nOtF0und Acesso em 20.jul.2009. Acesso em: 20.jul.2009.

SOUZA, J. 2009. Nos bastidores do poder. Blog do colunista do jornal Folha de S. Paulo Josias de Souza. São Paulo : Folha online. Disponível em : http://josiasdesouza.folha.blog.uol.com.br/Acesso em : 20.jul.2009.

THIOLLENT, M. J. M. 1982. Crítica metodológica, investigação social \& enquete operária. São Paulo : Polis.

SAMPEDRO, V. 2005. 13M : Multitudes Online. Madrid : Asociación de los libros de La Catarata.

\section{OUTRASFONTES}

Analfabetos em números - a revanche. 2009. Ciência em dia. Blog de Marcelo Leite, Blogs da Folha, 17.fev. Disponível em : http:// cienciaemdia.folha.blog.uol.com.br/arch2009-0215_2009-02-21.html. Acesso em : 17.jul.2009.

NARIZ GELADO. 2009. Blog "Nariz Gelado". Disponível em : http://narizgelado.apostos.com/ Acesso em : 22.jul.2009.

Em um ano, número de internautas residenciais cresce 50\% no Brasil. 2008. G1-Globo.com. Sub-sessão "internet", sessão "tecnologia", 22.fev. Disponível em : http://g1.globo.com/Noticias/ Tecnologia/0,,MUL310060-6174,00.html. Acesso em: 16.jul.2009.

NEAMP. Sítio do Núcleo de Estudos em Arte, Mídia \& Política do Programa de Estudos Pós-Graduados em Ciências Sociais da PUC-SP, Neamp, São
Paulo. Disponível em : http://www.pucsp.br/ neamp/ Acesso em : 6.ago.2009.

Número de brasileiros que lêem blogs cresce em 2008. 2009. IDG Now! Sub-sessão "Blog dos blogs", sessão "internet", 4.fev. Disponível em : http:// idgnow.uol.com.br/internet/blog_dos_blogs/ archive/2009/02/04/nmero-de-brasileiros-queleem-blogs-cresce-em-2008/. Acesso em : 16.jul.2009.

REVISTAAURORA. 2009. Sítio da Revista de Arte, Mídia e Política Autora. Aurora, São Paulo, PUCSP. Disponível em : http://www.pucsp.br/ revistaaurora/. Acesso em : 6.ago.2009.

TECHNORATI. 2008. State of the Blogosphere. Technorati. Disponível em : http://technorati.com/ blogging/state-of-the-blogosphere/. Acesso em : 6.ago.2009. 
ANEXO

PLANILHAS DE ANÁLISE DOS BLOGS

Planilha 1: Classificação dos Blogss de Política

\begin{tabular}{|l|l|l|l|l|l|}
\hline$N^{\circ}:$ & & Blog: & & Acesso: & \\
\hline Endereço: & \multicolumn{2}{|l|}{} \\
\hline
\end{tabular}

1.1 Localização dos Blogs:

\begin{tabular}{|l|l|l|l|l|l|}
\hline portal de internet & & sítio de mídia & & sítio de partido & \\
\hline independente & & sociedade civil & & &
\end{tabular}

12 - Perfil do 'blogueiro':

\begin{tabular}{|l|l|l|l|l|l|}
\hline jornalistas & & Políticos & & acadêmicos & \\
\hline pessoas desconhecidas & & Candidatos & & pessoas públicas & \\
\hline
\end{tabular}

Planilha 2: Análise da estrutura dos Blogs de Política

\begin{tabular}{|l|l|l|l|l|l|}
\hline$N^{\circ} .:$ & & Blog: & Acesso: & \\
\hline Endereço: & \multicolumn{2}{|l|}{} \\
\hline
\end{tabular}

2.1 Posts:

\begin{tabular}{|l|l|l|}
\cline { 2 - 3 } \multicolumn{1}{l|}{} & sim & não \\
\hline periodicidade & & \\
\hline existência de links & & \\
\hline mensagem externa & & \\
\hline
\end{tabular}

\subsection{Interatividade:}

\begin{tabular}{|c|c|c|c|c|c|}
\hline formato: & somente le & & $e-m$ & chat & fórum \\
\hline regras de & articipação: & $\operatorname{sim}$ & não & & \\
\hline respeito & s regras: & $\operatorname{sim}$ & não & & \\
\hline
\end{tabular}

2.3 Biografia:

\begin{tabular}{|l|l|l|l|l|l|l|l|l|}
\hline currículo: & completo & & parcial & & c/ foto & & ausente & \\
\hline
\end{tabular}

2.4 Links:

\begin{tabular}{|l|l|l|l|}
\hline internos & & Externos & \\
\hline
\end{tabular}

\subsection{Outros serviços:}

\begin{tabular}{|l|l|l|l|l|l|l|l|l|l|}
\hline entrevistas & & artigos & & enquetes & & \multicolumn{4}{|c|}{} \\
\hline imagens: & charge & & animações & & áudio & & vídeo & \\
\hline
\end{tabular}




\begin{tabular}{|l|l|l|l|l|l|l|l|l|}
\hline arquivos (consulta): & documentos & & fotos & & áudio & & vídeo & \\
\hline arquivos (download): & documentos & & fotos & & áudio & & vídeo & \\
\hline informaçóes úteis: & & \\
\hline outros: &
\end{tabular}

\section{Planilha 03: Análise do conteúdo dos mens agens}

\begin{tabular}{|l|l|l|l|l|l|}
\hline$N^{\circ} .:$ & & Blog: & & Acesso: & \\
\hline Endereço: & & & \\
\hline
\end{tabular}

\section{Título:}

\section{I - Enquad ramento:}

\begin{tabular}{|l|l|l|l|l|l|}
\hline informativo direto & & informativo indire to & & opinativo & \\
\hline avaliativo crítico & & irônico & & pos. político & \\
\hline propositivo & & avaliativo moral & & & \\
\cline { 1 - 3 } & &
\end{tabular}

II - Imagens dos post

Classificaçẫo das Imagens

\begin{tabular}{|l|l|l|l|l|}
\hline foto & & animaçẫo & outros & \\
\hline charge & & figura & & \\
\cline { 1 - 3 } & &
\end{tabular}

Funçẫo das Imagens

\begin{tabular}{|l|l|l|l|l|}
\hline ilustrativa & & humor & outras & \\
\cline { 1 - 3 } crítica & & informativa & & \\
\cline { 1 - 3 } & & &
\end{tabular}

III - Hipertextualidade dos mensagens

\begin{tabular}{|l|l|}
\hline Nr de links nos mensagens & \\
\hline Nr de links p/outros blogs & \\
\hline
\end{tabular}

\section{N - Temas tratados}

\begin{tabular}{|l|l|}
\hline tema: & \\
\hline sub-temas: & \\
\hline
\end{tabular}

\section{V-Comentários:}

número de comentários 
Planilha 04: Análise da interatividade (comentários)

\begin{tabular}{|l|l|l|l|l|l|}
\hline$N^{\circ}:$. & & Blog: & & Acesso: & \\
\hline Endereço: & & & \\
\hline data: __ _ _ _ _ norário: __
\end{tabular}

I - Enquadramento:

\begin{tabular}{|l|l|l|l|l|l|}
\hline informativo dire to & & informativo indireto & & opinativo & \\
\hline avaliativo crítico & & irónico & & pos. político & \\
\hline propositivo & & avaliativo moral & & disper sivo & \\
\hline
\end{tabular}


METHODOLOGY FOR RESEARCH ON POLITICAL BLOGS: ANALYSIS OF THE 2006 PRESIDENTIAL ELECTIONS AND THE “CANSEI” MOVEMENT

Cláudio Luis Penteado, Marcelo dos Santos and Rafael Araújo

In research on the relationship between politics and Internet, blogs may be seen as spaces for communication and political actors that bring a new dynamics to social relations. The present study discusses the use of this new tool and the implications that it has for our understanding of contemporary political life. We present a methodological proposal capable of providing aid for the analysis of blog structure, posts and interactivity. The method we suggest here does not have an explanatory nature but rather functions as a technique for data collection (reading) of political blogs. The information obtained should be analyzed within the wider theoretical framework that characterizes this research. This should enable us to avoid both empiricism and over- theorizing while adopting an innovative methodological approach that places priority on the technical and theoretical aspects that guide this investigation. Lastly, we present results obtained from applying this methodological proposal to the coverage of political blogs during the 2006 presidential elections and during the "Cansei ["I am sick and tired of this!'] movement. These results should make it clear that the proposed methodology is reliable and efficient, an effective tool for new research on political blogs.

Keywords: Internet; political blogs; electoral analysis; blog analysis; research methodology. 


\section{MÉTHODOLOGIE DE RECHERCHE DES BLOGS POLITIQUES: ANALYSE DES ÉLECTIONS PRÉSIDENTIELLES DE 2006 ET DU MOUVEMENT "J'EN AI ASSEZ!"}

Cláudio Luis Penteado, Marcelo dos Santos et Rafael Araújo

Dans les études des relations entre politique et Internet, il est possible de voir les blogs comme des espaces de communication et d'acteurs politiques ayant une nouvelle dimension pour les relations sociales. Cette étude discute de l'emploi de ce nouvel outil et de ses conséquences pour la compréhension du jeu politique contemporain. Nous présentons une proposition méthodologique favorisant l'analyse de la structure des blogs, les postages (posts) et l'interactivité. La méthode que nous suggérons ici n'a pas pourtant un esprit d'explication. Il s'agit plutôt d'une technique de collecte de données (lecture) des blogs politiques. Les informations obtenues doivent être analysées dans un cadre théorique plus large qui doit caractériser la recherche. Ainsi, nous croyons que nous évitons aussi bien l'empirisme que le théoricisme, en adoptant une approche méthodologique innovatrice qui privilégie les aspects techniques et théoriques sur lesquels s'appuyent la recherche. Enfin, nous présentons les résultats de l'utilisation de cette proposition méthodologique lorsque nous analysons les reportages des blogs de politique pendant les présidentielles de 2006 et pendant le mouvement « J'en ai assez ! ». Ces résultats montrent que cette méthodologie s'est avérée fiable et efficace, un outil performant de recherche pour d'autres enquêtes sur les blogs politiques.

MOTS-CLÉS : Internet ; blogs de politique ; analyse électorale ; analyse de blogs ; métholodogie de recherche. 